\title{
NQ01 Pro187Ser Polymorphism Confers to the Susceptibility of Prostate Cancer
}

\author{
Xiaofei Zhang1, Wei Jiao², Wenhua Zhang2* \\ ${ }^{1}$ Department of Cardiology, Qilu Hospital of Shandong University, Jinan, China \\ ${ }^{2}$ Department of Urology, Qilu Hospital of Shandong University, Jinan, China \\ Email: *wenhuazhang09@163.com
}

Received 20 November 2015; accepted 25 December 2015; published 28 December 2015

Copyright (C) 2015 by authors and Scientific Research Publishing Inc.

This work is licensed under the Creative Commons Attribution International License (CC BY).

http://creativecommons.org/licenses/by/4.0/

(c) (i) Open Access

\begin{abstract}
Increasing epidemiological studies were recently performed to assess the relationship of NAD(P)H: quinine oxidoreductase 1 (NQ01) Pro187Ser polymorphism and the risk of prostate cancer (PCa) to yield inconsistent results. In this study, we aimed to generate large-scale evidence on whether NQ01 Pro187Ser polymorphism conferred to the susceptibility of PCa. The database of PubMed was comprehensively reviewed until September $12^{\text {th }}, 2013$, without any linguistic limitation. Meta-analysis was complied in the codominant, dominant, recessive and allele models by either fixed or random effect models. Odds ratios $(\mathrm{OR})$ and $95 \%$ confidence intervals $(95 \% \mathrm{CI})$ were calculated to evaluate the strength of the association between the two. Finally, six eligible studies with 717 cases and 1764 controls were included. In overall analyses, significant associations were found in the dominant $(\mathrm{OR}=1.26,95 \% \mathrm{CI}=1.04-1.52, P=0.02)$, allele $(\mathrm{OR}=1.20,95 \% \mathrm{CI}=1.03$ $1.40, P=0.02)$ and the heterozygous codominant $(\mathrm{OR}=1.24,95 \% \mathrm{CI}=1.02-1.52, P=0.03)$ models. Also, significant results were found in the stratified analyses by Hardy-Weinberg equilibrium (HWE). Still, subgroup analysis showed an increased risk of PCa in Asian rather than Caucasian population. Besides, NQO Pro187Ser polymorphism correlated with a heightened risk of PCa in the hospital-based studies. Our study indicated that NQ01 functional Pro187Ser polymorphism could be a potentially genetic biomarker for the risk of $\mathrm{PCa}$, especially in Asian population.
\end{abstract}

\section{Keywords}

NQ01, Polymorphism, Prostate, Cancer, Meta-Analysis

\footnotetext{
${ }^{*}$ Corresponding author.
} 


\section{Introduction}

Cancer is a major public health problem worldwide and one of the leading causes of death [1]. The newly diagnosed and death for prostate cancer (PCa) were 217,730 and 32,050 respectively in USA [2]. However, PCa is a complex process and its exact mechanism has not yet been fully elucidated. Genetic variation, life style, and environmental factors are widely considered to be the most essential factors in carcinogenesis [3]. Therefore, screening feasible nucleotide and protein markers is of provital significance.

NAD(P)H:quinine oxidoreductase 1 (NQO1), formerly known as DT-diaphorase, is a vital flavoenzyme in xenobiotic metabolism. NQO1 is a cytoplasmic two-electron reductase using either NADPH or NADH as an electron donor. It catalyzes mutagenic and carcinogenic quinones into less toxic and reactive hydroquinones and prevents the one electron reduction of quinones as well as the production of radical species [4]. On the other hand, NQO1 was also found to have the capacity of bioactivating cytotoxic compounds and environmental procarcinogens. The actual effect of NQO1 as either an activation or detoxification enzyme largely depends on the substrate. It is convinced that the biological implications of NQO1 are of an increasing interest in the development of PCa.

Genetic differences are of great significance to determine interindividual variation of pathogenesis of PCa. The gene encoding NQO1 locates on chromosome 16q22.1, spans 17,230 bp, consists of 6 exons and 5 introns, encodes 2912 bp cDNA, and translates the protein of 274 amino acids [5]. To date, hundreds of single nucleotide polymorphisms (SNP) of the human NQO1 gene have been identified. NQO1 Pro187Ser polymorphism (P187S, C609T, rs1800566) is in exon 6, a C to T mutation at position 609 of the NQO1 cDNA resulting in a proline to serine amino acid substitution at position 187 in the protein [6]. It has been widely evaluated and inconsistently associated with PCa [7]-[12]. Stoehr et al. concluded that NQO1 Pro187Ser polymorphism neither significantly increased the risk of PCa, nor closely correlated with the stage or Gleason score of the tumor [9]. Steiner et al. suggested that NQO1 Pro187Ser polymorphism failed to act as a risk modifier for PCa [12]. Similarly, Steinbrecher et al. and Hamajima et al. deduced that minor association existed between NQO1 Pro187Ser polymorphism and the susceptibility of PCa [7] [11]. Ergen et al. reported that NQO1 Pro187Ser polymorphism affected the serum PSA and alkaline phosphatase levels [10]. However, Mandal et al. indicated that NQO1 Pro187Ser polymorphism might play a role in PCa risk [8]. So, it is prerequisite for us to get a better understanding of NQO1 Pro187Ser polymorphism on PCa risk, especially when conflicting findings still exist. In the current study, we performed a quantitative synthesis of the published case-control studies on the association of NQO1 Pro187Ser polymorphism and PCa risk to gain more creditable evidence.

\section{Materials and Methods}

\subsection{Publication Identification}

Published studies exploring the relationship of the NQO1 Pro187Ser polymorphism with the risk of PCa were retrieved through the PubMed database (last search September $12^{\text {th }}, 2013$ ). We did not set any linguistic limitation. The following keywords in the title/abstract text were used: "NQO1", "NAD(P)H dehydrogenase", "NAD(P)H:quinine oxidoreductase”, “Quinone oxidoreductase”, “Quinone reductase”, "DTD”, "DT-diaphorase”, "rs1800566" and "prostate", "prostatic". Finally, 61 potentially relevant studies were obtained through systematically searching the database of PubMed.

\subsection{Inclusion and Exclusion Criteria}

Studies were eligible for inclusion if (a) the studies had to be case-control studies; (b) the studies provided the number of various genotypes for both case and control groups; (c) human studies. The exclusion criteria of the meta-analysis were: (a) not case-control studies; (b) animal studies; (c) reviews; (d) editorial comments; (e) replicate data.

\subsection{Data Extraction}

Two investigators independently reviewed and extracted the data from included reports, and the results were further confirmed with another investigator. We collected the information of qualified studies, such as the first author, year of publication, the ethnicity of the study population, the country conducting the study, sex, source 
and characteristics of controls and cases, genotyping methods, the number of genotypes and alleles, HardyWeinberg Equilibrium (HWE) by a standard form. The results were orderly shown in Table 1.

\subsection{Statistical Analysis}

The genetic differences of genotypes and alleles in NQO1 Pro187Ser polymorphism for the control groups of Caucasian and Asian populations were calculated by Pearson chi-square test. The distributions of genotypes and alleles were considered to be different, if $P<0.05$. We extracted data for HWE from included studies for NQO1 Pro187Ser polymorphism, and calculated HWE by the chi-square test in case of failing to get the information. Still, $P$-value less than 0.05 was considered to be statistically significant. The strength of the associations between NQO1 Pro187Ser polymorphism and PCa susceptibility were figured out in the dominant (TT + CT vs $\mathrm{CC}$ ), the recessive ( $\mathrm{TT}$ vs CT + CC), the allele ( $\mathrm{T}$ vs $\mathrm{C}$ ), the heterozygous codominant (CT vs CC) and the homozygous codominant (TT vs CC) models by ORs and 95\%CI, respectively. Meanwhile, subgroup analyses were carried out based on ethnicity, HWE, sex, control sources and smoking status. The heterogeneity test was assessed by chi-square based $Q$ statistic and was considered to be statistically significant if $P<0.10$. The pooled ORs were calculated by either a fixed effect model (the Mantel-Haenszel method) [13] or a random effect model (the Dersimonian-Laird method) [14] based on the heterogeneity among studies. The potential publication bias was appraised by the funnel plot. Statistical analyses were performed in SPSS 16.0 software (SPSS Inc, Chicago, IL) and RevMan 5.1 software (The Cochrane Collaboration). All probabilities were two-tailed.

\section{Results}

\subsection{Main Characteristics of Eligible Studies}

A comprehensive search of the literature was performed to identify studies on NQO1 Pro187Ser polymorphism and the risk of PCa. 61 relevant articles were got for further screening. After checking titles, abstracts and fulltexts, 6 studies with 717 cases and 1764 controls were finally qualified. Among qualified studies, two studies included participants of Asian descent, and the other four of Caucasian. Control group in the study of Steinbrecher et al. deviated from HWE. And characteristics of all eligible studies included in the meta-analysis were listed in Table 1.

\subsection{Frequency of NQ01 Pro187Ser Polymorphism in Asian and Caucasian Populations}

As for NQO1 Pro187Ser polymorphism, 874 controls of Caucasian population and 890 controls of Asian population were included in the final meta-analysis. The frequencies of the CC, CT, and TT genotypes for Caucasian were $67.39 \%$, $28.60 \%$, $0.04 \%$ respectively, while those for Asian were $45.39 \%, 40.22 \%$, and $14.38 \%$. A huge variation was observed across control subjects. The frequencies of the $\mathrm{C}$ and $\mathrm{T}$ alleles for Caucasian were 81.69\%, 18.31\%, while those for Asian were $65.51 \%$ and $34.49 \%$. More individuals carried $\mathrm{T}$ allele in Asian than those in Caucasian population $(P<0.05)$. The frequencies of the alleles for NQO1 Pro187Ser polymorphism were obviously different between Caucasian and Asian groups $(P<0.05)$.

Table 1. Characteristics of eligible studies included in the meta-analysis.

\begin{tabular}{|c|c|c|c|c|c|c|c|c|c|c|c|}
\hline \multirow{2}{*}{ First author } & \multirow{2}{*}{ Year } & \multirow{2}{*}{ Country } & \multirow{2}{*}{ Ethnicity } & \multirow{2}{*}{$\begin{array}{l}\text { Genotyping } \\
\text { method }\end{array}$} & \multirow{2}{*}{$\begin{array}{l}\text { Control } \\
\text { source }\end{array}$} & \multirow{2}{*}{$\begin{array}{l}\text { Control } \\
\text { gender }\end{array}$} & \multicolumn{4}{|c|}{ Genotype frequency (case/control) } & \multirow{2}{*}{$\begin{array}{l}\text { HWE } \\
\text { Y/N }\end{array}$} \\
\hline & & & & & & & Pro/Pro(n) & Pro/Ser(n) & Ser/Ser(n) & Ser(\%) & \\
\hline Mandal RK & 2012 & India & Asian & PCR-RFLP & Hospital & M & $105 / 164$ & $67 / 72$ & $23 / 14$ & $28.97 / 20.00$ & $\mathrm{Y}$ \\
\hline Stoehr CG & 2012 & Germany & Caucasian & PCR-RFLP & Hospital & M & 76/166 & $37 / 60$ & $6 / 6$ & 20.59/15.52 & $\mathrm{Y}$ \\
\hline Steinbrecher A & 2010 & Germany & Caucasian & MS & Population & M & $163 / 333$ & $80 / 133$ & $5 / 26$ & $18.15 / 18.80$ & $\mathrm{~N}$ \\
\hline Ergen HA & 2007 & Turkey & Caucasian & PCR-RFLP & Hospital & M & $23 / 23$ & $17 / 26$ & $5 / 1$ & $30.00 / 28.00$ & Y \\
\hline Hamajima N & 2002 & Japan & Asian & PCR-CTPP & Hospital & $\mathrm{M} / \mathrm{F}$ & $17 / 240$ & $30 / 286$ & $9 / 114$ & $42.86 / 40.16$ & $\mathrm{Y}$ \\
\hline Steiner $\mathrm{M}$ & 1999 & Germany & Caucasian & PCR-RFLP & Population & $\mathrm{M} / \mathrm{F}$ & $37 / 67$ & $15 / 31$ & $2 / 2$ & $17.59 / 17.50$ & $\mathrm{Y}$ \\
\hline
\end{tabular}

M: Male; F: Female; RFLP: Restriction fragment length polymorphism; MS: MassArray system; CTPP: Confronting two-pair primers; HWE: HardyWeinberg equilibrium; Y: Studies with controls in HWE; N: Studies with controls deviating from HWE. 


\subsection{Main Results of Meta-Analysis}

Finally, we conducted meta-analysis of NQO1 Pro187Ser polymorphism and PCa based on six case-control studies. The significant association was found in the dominant model (TT + CT vs CC: OR $=1.26,95 \% \mathrm{CI}=1.04$ $1.52, P=0.02$ ), the allele model (T vs C: $\mathrm{OR}=1.20,95 \% \mathrm{CI}=1.03-1.40, P=0.02$ ) (Figure 1 ) and the heterozygous codominant model (CT vs CC: $\mathrm{OR}=1.24,95 \% \mathrm{CI}=1.02-1.52, P=0.03$ ) (Table 2). When only including the study conforming to HWE, significant associations were also found in the dominant, the recessive, the allele and the homozygous codominant model $(P<0.05)$ (Table 2).

In the following study, we conducted the stratified analysis by ethnicity, the source of control and sex. Significant associations were found in stratified analysis of Asian population in the dominant model (TT + CT vs CC: $\mathrm{OR}=1.55,95 \% \mathrm{CI}=1.12-2.14, P=0.008)$, the allele model $(\mathrm{T}$ vs $\mathrm{C}: \mathrm{OR}=1.41,95 \% \mathrm{CI}=1.11-1.80, P=$ 0.005 ), the homozygous codominant model (TT vs CC: $\mathrm{OR}=1.82,95 \% \mathrm{CI}=1.07-3.08, P=0.03$ ) and the heterozygous codominant model (CT vs CC: $\mathrm{OR}=1.46,95 \% \mathrm{CI}=1.04-2.06, P=0.03$ ) (Table 2). While, there was no association between NQO1 functional Pro187Ser polymorphism and the risk of PCa in Caucasian population (all $P>0.05$ ). Similarly, significant associations were found in the subgroup analysis of hospital but population based case-control studies (Table 2). In the analysis of studies recruiting only male as control group, predominant associations were found in the dominant model (TT + CT vs CC: $\mathrm{OR}=1.27,95 \% \mathrm{CI}=1.03-1.57$, $P=0.02)$ and the heterozygous codominant model (CT vs CC: $\mathrm{OR}=1.26,95 \% \mathrm{CI}=1.01-1.57, P=0.04$ ) (Table 2).

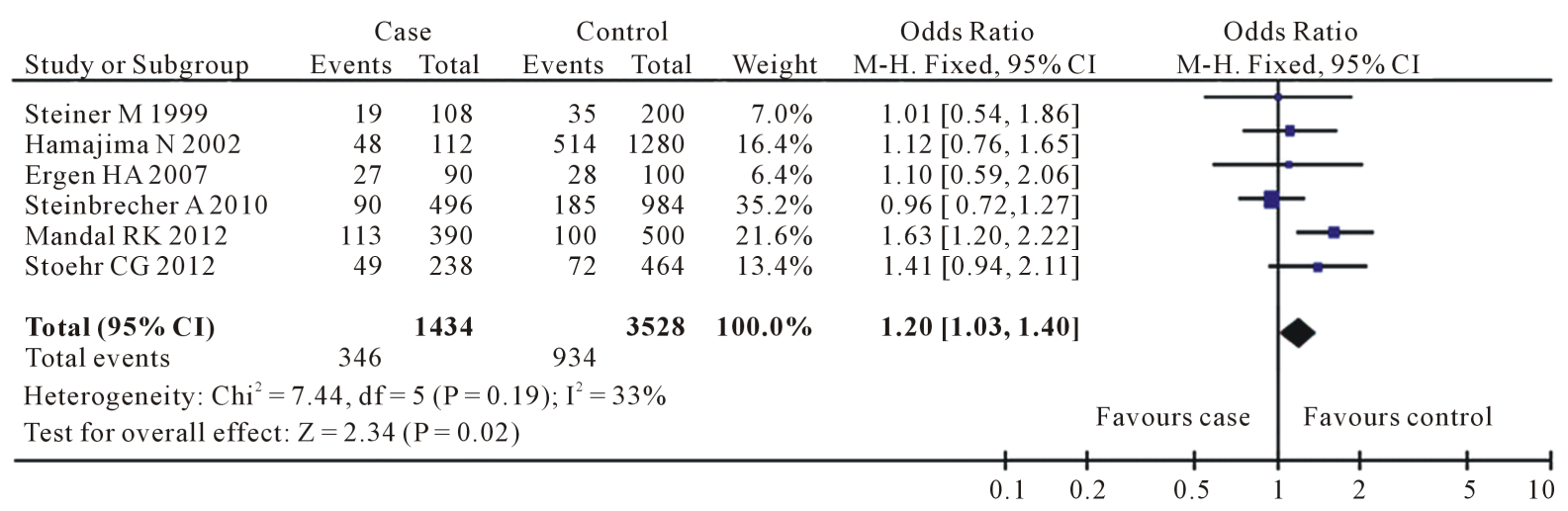

Figure 1. The significant association was found in the dominant model and the allele model.

Table 2. Main results of meta-analysis for the association of NQO1 Pro187Ser polymorphism and prostate cancer risk.

\begin{tabular}{|c|c|c|c|c|c|c|c|c|c|c|c|c|c|c|c|}
\hline \multirow[b]{2}{*}{ Group } & \multicolumn{3}{|c|}{ TT + CT vs CC } & \multicolumn{3}{|c|}{ TT vs CT + CC } & \multicolumn{3}{|c|}{ T vs C } & \multicolumn{3}{|c|}{ TT vs CC } & \multicolumn{3}{|c|}{ CT vs CC } \\
\hline & $\begin{array}{c}\text { OR } \\
(95 \% \mathrm{Cl})\end{array}$ & $P_{\mathrm{h}}$ & $P_{\mathrm{m}}$ & $\begin{array}{c}\text { OR } \\
(95 \% \mathrm{CI})\end{array}$ & $P_{\mathrm{h}}$ & $P_{\mathrm{m}}$ & $\begin{array}{c}\text { OR } \\
(95 \% \mathrm{CI})\end{array}$ & $P_{\mathrm{h}}$ & $P_{\mathrm{m}}$ & $\begin{array}{c}\text { OR } \\
(95 \% \mathrm{CI})\end{array}$ & $P_{\mathrm{h}}$ & $P_{\mathrm{m}}$ & $\begin{array}{c}\text { OR } \\
(95 \% \mathrm{Cl})\end{array}$ & $P_{\mathrm{h}}$ & $P_{\mathrm{m}}$ \\
\hline Overall & $\begin{array}{c}1.26 \\
(1.04-1.52)\end{array}$ & 0.46 & 0.02 & $\begin{array}{c}1.33 \\
(0.66-2.70)\end{array}$ & 0.03 & 0.43 & $\begin{array}{c}1.20 \\
(1.03-1.40)\end{array}$ & 0.19 & 0.02 & $\begin{array}{c}1.46 \\
(0.72-2.94)\end{array}$ & 0.04 & 0.29 & $\begin{array}{c}1.24 \\
(1.02-1.52)\end{array}$ & 0.54 & 0.03 \\
\hline HWE & $\begin{array}{c}1.35 \\
(1.07-1.72)\end{array}$ & 0.47 & 0.01 & $\begin{array}{c}1.66 \\
(1.09-2.52)\end{array}$ & 0.29 & 0.02 & $\begin{array}{c}1.34 \\
(1.11-1.61)\end{array}$ & 0.46 & 0.002 & $\begin{array}{c}1.98 \\
(1.26-3.12)\end{array}$ & 0.55 & 0.003 & $\begin{array}{c}1.25 \\
(0.98-1.61)\end{array}$ & 0.40 & 0.08 \\
\hline Caucasian & $\begin{array}{c}1.12 \\
(0.88-1.42)\end{array}$ & 0.60 & 0.36 & $\begin{array}{c}1.39 \\
(0.41-4.76)\end{array}$ & 0.04 & 0.60 & $\begin{array}{c}1.08 \\
(0.88-1.32)\end{array}$ & 0.48 & 0.48 & $\begin{array}{c}1.37 \\
(0.42-4.43)\end{array}$ & 0.05 & 0.60 & $\begin{array}{c}1.14 \\
(0.89-1.46)\end{array}$ & 0.42 & 0.29 \\
\hline Asian & $\begin{array}{c}1.55 \\
(1.12-2.14)\end{array}$ & 0.63 & 0.008 & $\begin{array}{c}1.42 \\
(0.57-3.57)\end{array}$ & 0.07 & 0.45 & $\begin{array}{c}1.41 \\
(1.11-1.80)\end{array}$ & 0.14 & 0.005 & $\begin{array}{c}1.82 \\
(1.07-3.08)\end{array}$ & 0.14 & 0.03 & $\begin{array}{c}1.46 \\
(1.04-2.06)\end{array}$ & 0.96 & 0.03 \\
\hline Population & $\begin{array}{c}1.06 \\
(0.79-1.43)\end{array}$ & 0.69 & 0.69 & $\begin{array}{c}0.48 \\
(0.21-1.11)\end{array}$ & 0.15 & 0.09 & $\begin{array}{c}0.97 \\
(0.75-1.24)\end{array}$ & 0.88 & 0.79 & $\begin{array}{c}0.50 \\
(0.22-1.18)\end{array}$ & 0.18 & 0.11 & $\begin{array}{c}1.16 \\
(0.85-1.57)\end{array}$ & 0.41 & 0.34 \\
\hline Hospital & $\begin{array}{c}1.42 \\
(1.10-1.83)\end{array}$ & 0.50 & 0.006 & $\begin{array}{c}1.65 \\
(1.07-2.53)\end{array}$ & 0.17 & 0.02 & $\begin{array}{c}1.38 \\
(1.13-1.68)\end{array}$ & 0.43 & 0.001 & $\begin{array}{c}1.99 \\
(1.25-3.17)\end{array}$ & 0.39 & 0.004 & $\begin{array}{c}1.31 \\
(1.01-1.71)\end{array}$ & 0.39 & 0.04 \\
\hline Male & $\begin{array}{c}1.27 \\
(1.03-1.57)\end{array}$ & 0.27 & 0.02 & $\begin{array}{c}1.52 \\
(0.52-4.44)\end{array}$ & 0.01 & 0.45 & $\begin{array}{c}1.26 \\
(0.95-1.67)\end{array}$ & 0.08 & 0.12 & $\begin{array}{c}1.59 \\
(0.54-4.68)\end{array}$ & 0.01 & 0.40 & $\begin{array}{c}1.26 \\
(1.01-1.57)\end{array}$ & 0.41 & 0.04 \\
\hline
\end{tabular}

HWE: Hardy-Weinberg equilibrium; RFLP: Restriction fragment length polymorphism; OR: Odd ratio; CI: Confidence interval; $P_{\mathrm{h}}: P$ value for heterogeneity; $P_{\mathrm{m}}: P$ value for meta-analysis. 


\subsection{Heterogeneity Test and Publication Bias Test}

In the overall analysis, significant heterogeneity $(P<0.10)$ was observed in the recessive model $\left(I^{2}=60 \%, P=\right.$ $0.03)$ and homozygous codominant model $\left(I^{2}=57 \%, P=0.04\right)$. And the results of heterogeneity test for subgroup analyses were shown in Table 2. No evidence of publication bias was found for NQO1 Pro187Ser polymorphism and PCa risk with funnel plot. The funnel plot for the publication bias of the allele analysis in overall population was listed in Figure 2.

\section{Discussion}

NQO1 is foremostly supposed to be an essential defense against cancers, and the mechanisms were described from various aspects. In-vitro study revealed that NQO1 specifically got rid of the generation of benzo(a)pyrene quinone-DNA adducts produced by CYP1A1 and P450 reductase [4]. In addition, NQO1 can play its role as a chaperone to stabilize the tumor suppressor protein p53 by inhibiting proteasomal degradation pathway through direct interaction [15] [16]. In-vivo study suggested that mice with NQO1 knockout showed a much higher frequency of chemically induced tumor compared with wild-type mice [17] [18]. Moreover, NQO1 was reported to show NAD(P)H dependent superoxide scavenging activity [19] [20]. NQO1 functional Pro187Ser polymorphism localizes in exon 6. A C to T mutation at position 609 of the NQO1 cDNA resulted in a proline to serine amino acid substitution at position 187 in the protein. It has been widely evaluated to be associated with the susceptibility of cancers, including PCa. However, it was found to be inconsistently associated with cancer risk. It is inferred that the conflicting findings could be secondary to ethnic background, the small sample size or designing method. Meta-analysis is a powerful method for increasing statistical power by pooling the results of individual studies [21]-[24]. To date, the role of NQO1 Pro187Ser polymorphism has been verified in several types of cancers with meta-analysis [25]-[28]. In this meta-analysis, we searched all studies about the relationship of NQO1 Pro187Ser polymorphism and PCa risk to pool their conclusions together, expecting to get a more robust deduction.

In overall analysis, we conducted meta-analysis of NQO1 Pro187Ser polymorphism and PCa based on all eligible case-control studies. The significant association was found in the dominant model (TT + CT vs CC: OR = $1.26,95 \% \mathrm{CI}=1.04-1.52, P=0.02$ ), the allele model ( $\mathrm{T}$ vs $\mathrm{C}: \mathrm{OR}=1.20,95 \% \mathrm{CI}=1.03-1.40, P=0.02$ ), as well as the heterozygous codominant model (CT vs CC: $\mathrm{OR}=1.24,95 \% \mathrm{CI}=1.02-1.52, P=0.03$ ). It is recommeded that the analysis based on the studies in HWE would be more reliable [29]. When only including the study conforming to HWE, significant associations were also found in the dominant (TT + CT vs CC: OR = $1.35,95 \% \mathrm{CI}=1.07-1.72, P=0.01)$, the recessive $(\mathrm{TT}$ vs $\mathrm{CT}+\mathrm{CC}: \mathrm{OR}=1.66,95 \% \mathrm{CI}=1.09-2.52, P=0.02)$, the allele (T vs C: $\mathrm{OR}=1.34,95 \% \mathrm{CI}=1.11-1.61, P=0.002$ ) and the homozygous codominant model (TT vs CC: $\mathrm{OR}=1.98,95 \% \mathrm{CI}=1.26-3.12, P=0.003$ ). Several studies demonstrated that individual with TT genotype were insufficient in NQO1 protein and activity [6] [30]. Evidence showed that both NQO1 wild and mutant

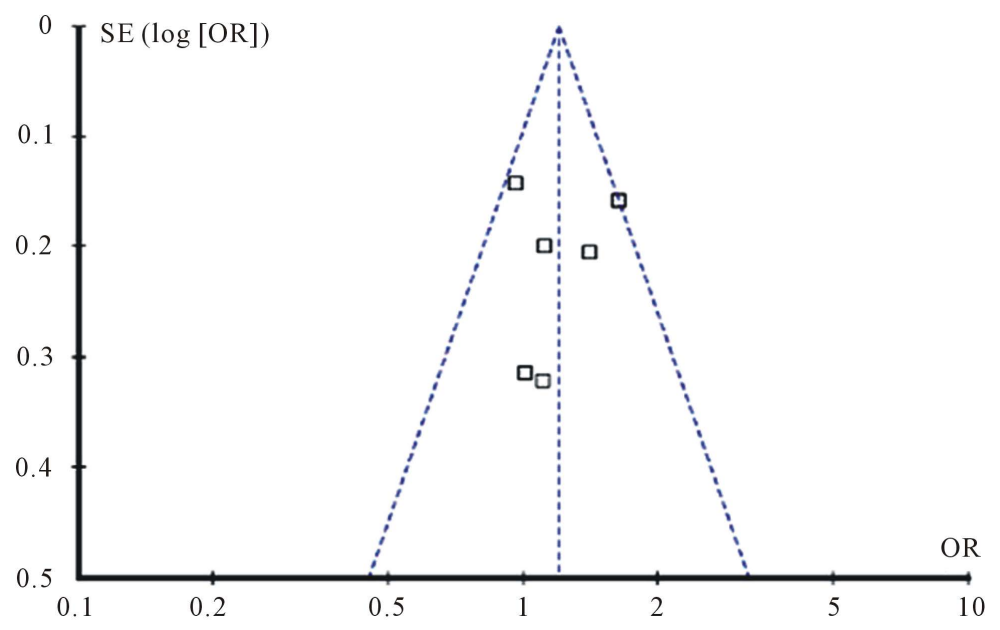

Figure 2. The funnel plot for the publication bias of the allele analysis in overall population was listed. 
homozygous had no difference in the half-life of NQO1 mRNA and the efficiency to transcribe and translate the full-length protein [31]. However, mutant NQO1 was rapidly degraded by ubiquitination and proteasome pathway [31], while wild-type NQO1 was stable. And the enzyme activity of CT genotype is between the two homozygous [32]. Thereafter, the mutant allele of NQO1, which results in reduced enzymatic activity [33], may contribute to individual's susceptibility of PCa.

Still, ethnicity is an essential biological factor that may influence NQO1 Pro187Ser polymorphism through gene-gene interactions. In this study, 874 controls of Caucasian origins and 890 of Asian origins were included in the final meta-analysis. The frequencies of the CC, CT, and TT genotypes for Caucasian were $67.39 \%$, 28.60\%, 0.04\%, while those for Asian were 45.39\%, 40.22\%, and 14.38\% respectively. More individuals carried $\mathrm{T}$ allele in Asian (34.49\%) than those in Caucasian $(18.31 \%)$ population $(P<0.05)$. In the stratified analysis of ethnicity, significant associations only existed in Asian population. Individuals with TT/CT genotypes had a 1.55 fold higher risk than those with CC genotype. And individuals with TT genotype conferred a 1.82 fold higher risk than those with CC genotype. T allele was found to have a 1.41 fold higher risk than $\mathrm{C}$ allele. There were no significant associations in Caucasian population.

Similarly, significant associations were found in the subgroup analysis of hospital but population based case-control studies. In the analysis of studies recruiting only male as control group, predominant associations were found in the dominant model (TT + CT vs CC: $\mathrm{OR}=1.27,95 \% \mathrm{CI}=1.03-1.57, P=0.02$ ) and the heterozygous codominant model (CT vs CC: $\mathrm{OR}=1.26,95 \% \mathrm{CI}=1.01-1.57, P=0.04$ ).

Nevertheless, there are still some limitations inherent in the current study as other published meta-analyses that should be acknowledged. Firstly, NQO1 was also found to have the capacity of both detoxifying and bioactivating cytotoxic compounds and environmental procarcinogens [34]. The actual effect of NQO1 as either an activation or detoxification enzyme largely depends on the substrate. However, most of our final results were based on unadjusted estimates. A more precise analysis stratified by carcinogenic factors should be conducted when ample studies were available. Secondly, the number of eligible studies as well as that of included cases and controls for some of the total and subgroup analyses was not sufficient enough. Thereafter, we would be effectively underpowered to get significant associations. Thirdly, the genetic distribution of the controls in the study of Steinbrecher et al. included in our study was not consistent with HWE, which is an influential factor in meta-analysis. The results of genetic association, which tend to be altered by including and excluding the study, should be interpreted with caution.

In summary, we provide genetic evidence that NQO1 Pro187Ser polymorphism may play a role in the higher risk of PCa. And, subgroup analysis showed an increased risk in Asian population. Further analyses should be performed with additional well-designed studies of larger sample size and multiplicate ethnicity. Especially, in-vitro and in-vivo molecular studies in consideration of gene-gene and gene-environment interactions are welcomed to figure out the effects of NQO1 Pro187Ser polymorphism on the occurrence of PCa.

\section{Conclusion}

Significant results were found in the stratified analyses by HWE. Still, subgroup analysis showed an increased risk of PCa in Asian rather than Caucasian population. Besides, NQO Pro187Ser polymorphism correlated with a heightened risk of PCa in the hospital-based studies. Our study indicated that NQO1 functional Pro187Ser polymorphism could be a potentially genetic biomarker for the risk of PCa, especially in Asian population.

\section{References}

[1] Ferlay, J., Parkin, D.M. and Steliarova-Foucher, E. (2010) Estimates of Cancer Incidence and Mortality in Europe in 2008. European Journal of Cancer, 46, 765-781. http://dx.doi.org/10.1016/j.ejca.2009.12.014

[2] Jemal, A., Siegel, R., Xu, J. and Ward, E. (2010) Cancer Statistics, 2010. CA: A Cancer Journal for Clinicians, 60, 277-300. http://dx.doi.org/10.3322/caac.20073

[3] Bostwick, D.G., Burke, H.B., Djakiew, D., Euling, S., Ho, S.M., Landolph, J., Morrison, H., Sonawane, B., Shifflett, T., Waters, D.J. and Timms, B. (2004) Human Prostate Cancer Risk Factors. Cancer, 101, 2371-2490. http://dx.doi.org/10.1002/cncr.20408

[4] Joseph, P. and Jaiswal, A.K. (1994) Nad(p)h:Quinone Oxidoreductase1 (dt Diaphorase) Specifically Prevents the Formation of Benzo[a]Pyrene Quinone-DNA Adducts Generated by Cytochrome p4501a1 and p450 Reductase. Proceedings of the National Academy of Sciences of the United States of America, 91, 8413-8417. 
http://dx.doi.org/10.1073/pnas.91.18.8413

[5] Jaiswal, A.K., McBride, O.W., Adesnik, M. and Nebert, D.W. (1988) Human Dioxin-Inducible Cytosolic nad(p)h: Menadione Oxidoreductase. Cdna Sequence and Localization of Gene to Chromosome 16. Journal of Biological Chemistry, 263, 13572-13578.

[6] Traver, R.D., Siegel, D., Beall, H.D., Phillips, R.M., Gibson, N.W., Franklin, W.A. and Ross, D. (1997) Characterization of a Polymorphism in nad(p)h:Quinone Oxidoreductase (dt-Diaphorase). British Journal of Cancer, 75, 69-75. http://dx.doi.org/10.1038/bjc.1997.11

[7] Steinbrecher, A., Rohrmann, S., Timofeeva, M., Risch, A., Jansen, E. and Linseisen, J. (2010) Dietary Glucosinolate Intake, Polymorphisms in Selected Biotransformation Enzymes, and Risk of Prostate Cancer. Cancer Epidemiology, Biomarkers \& Prevention, 19, 135-143. http://dx.doi.org/10.1158/1055-9965.EPI-09-0660

[8] Mandal, R.K., Nissar, K. and Mittal, R.D. (2012) Genetic Variants in Metabolizing Genes nqo1, nqo2, mthfr and Risk of Prostate Cancer: A Study from North India. Molecular Biology Reports, 39, 11145-11152. http://dx.doi.org/10.1007/s11033-012-2023-z

[9] Stoehr, C.G., Nolte, E., Wach, S., Wieland, W.F., Hofstaedter, F., Hartmann, A. and Stoehr, R. (2012) Nad(p)h: Quinone Oxidoreductase 1 (nqo1) p187s Polymorphism and Prostate Cancer Risk in Caucasians. International Journal of Molecular Sciences, 13, 10959-10969. http://dx.doi.org/10.3390/ijms130910959

[10] Ergen, H.A., Gormus, U., Narter, F., Zeybek, U., Bulgurcuoglu, S. and Isbir, T. (2007) Investigation of nad(p)h: Quinone Oxidoreductase 1 (nqo1) c609t Polymorphism in Prostate Cancer. Anticancer Research, 27, 4107-4110.

[11] Hamajima, N., Matsuo, K., Iwata, H., Shinoda, M., Yamamura, Y., Kato, T., Hatooka, S., Mitsudomi, T., Suyama, M., Kagami, Y., Ogura, M., Ando, M., Sugimura, Y. and Tajima, K. (2002) NAD(P)H:Quinone Oxidoreductase 1 (NQO1) C609T Polymorphism and the Risk of Eight Cancers for Japanese. International Journal of Clinical Oncology, 7, 103108.

[12] Steiner, M., Hillenbrand, M., Borkowsi, M., Seiter, H. and Schuff-Werner, P. (1999) 606 C $\rightarrow$ T Polymorphism in NAD(P)H:Quinone Oxidoreductase Gene in Patients with Prostatic Adenocarcinoma or Benign Prostatic Hyperplasia. Cancer Letters, 135, 67-71. http://dx.doi.org/10.1016/S0304-3835(98)00269-9

[13] Mantel, N. and Haenszel, W. (1959) Statistical Aspects of the Analysis of Data from Retrospective Studies of Disease. Journal of the National Cancer Institute, 22, 719-748.

[14] Der Simonian, R. and Laird, N. (1986) Meta-Analysis in Clinical Trials. Controlled Clinical Trials, 7, 177-188. http://dx.doi.org/10.1016/0197-2456(86)90046-2

[15] Asher, G., Lotem, J., Cohen, B., Sachs, L. and Shaul, Y. (2001) Regulation of p53 Stability and p53-Dependent Apoptosis by NADH Quinone Oxidoreductase 1. Proceedings of the National Academy of Sciences of the United States of America, 98, 1188-1193. http://dx.doi.org/10.1073/pnas.98.3.1188

[16] Anwar, A., Dehn, D., Siegel, D., Kepa, J.K., Tang, L.J., Pietenpol, J.A. and Ross, D. (2003) Interaction of Human NAD(P)H:Quinone Oxidoreductase 1 (NQO1) with the Tumor Suppressor Protein p53 in Cells and Cell-Free Systems. Journal of Biological Chemistry, 278, 10368-10373. http://dx.doi.org/10.1074/jbc.M211981200

[17] Long, D.J., Waikel, R.L., Wang, X.J., Perlaky, L., Roop, D.R. and Jaiswal, A.K. (2000) NAD(P)H:Quinone Oxidoreductase 1 Deficiency Increases Susceptibility to Benzo(a)pyrene-Induced Mouse Skin Carcinogenesis. Cancer Research, 60, 5913-5915.

[18] Iskander, K., Gaikwad, A., Paquet, M., Long, D.J., Brayton, C., Barrios, R. and Jaiswal, A.K. (2005) Lower Induction of p53 and Decreased Apoptosis in NQO1-Null Mice Lead to Increased Sensitivity to Chemical-Induced Skin Carcinogenesis. Cancer Research, 65, 2054-2058. http://dx.doi.org/10.1158/0008-5472.CAN-04-3157

[19] Siegel, D., Gustafson, D.L., Dehn, D.L., Han, J.Y., Boonchoong, P., Berliner, L.J. and Ross, D. (2004) NAD(P)H: Quinone Oxidoreductase 1: Role as a Superoxide Scavenger. Molecular Pharmacology, 65, 1238-1247. http://dx.doi.org/10.1124/mol.65.5.1238

[20] Dinkova-Kostova, A.T. and Talalay, P. (2010) NAD(P)H:Quinone Acceptor Oxidoreductase 1 (NQO1), a Multifunctional Antioxidant Enzyme and Exceptionally Versatile Cytoprotector. Archives of Biochemistry and Biophysics, 501, 116-123. http://dx.doi.org/10.1016/j.abb.2010.03.019

[21] Egger, M., Smith, G.D. and Phillips, A.N. (1997) Meta-Analysis: Principles and Procedures. BMJ, 315, $1533-1537$. http://dx.doi.org/10.1136/bmj.315.7121.1533

[22] Li, D., Liu, J., Zhang, W., Ren, J., Yan, L., Liu, H. and Xu, Z. (2013) Association between HIF1A P582S and A588T Polymorphisms and the Risk of Urinary Cancers: A Meta-Analysis. PLoS ONE, 8, e63445. http://dx.doi.org/10.1371/journal.pone.0063445

[23] Li, D., Liu, H., Yan, L., Tang, Y., Ren, J. and Xu, Z. (2012) Lack of Association between Hogg1 Ser326Cys Polymorphism and the Risk of Bladder Cancer: A Meta-Analysis. Urologia Internationalis, 88, 88-94. http://dx.doi.org/10.1159/000331931 
[24] Li, D., Tian, T., Guo, C., Ren, J., Yan, L., Liu, H. and Xu, Z. (2012) No Association of the MTHFR Gene A1298C Polymorphism with the Risk of Prostate Cancer: A Meta-Analysis. Experimental and Therapeutic Medicine, 3, 493498.

[25] Liu, K., Tian, H., Yu, K.Z., Shen, W.Y., Mao, Z.C., Jin, C.H., Pan, H.B. and He, J.X. (2013) Association between NQO1 Pro187Ser Polymorphism and Esophageal Cancer: A Meta-Analysis. Tumor Biology, 35, 2063-2068.

[26] Zhao, H., Zhu, F., Sun, J. and Meng, X. (2013) Meta-Analysis of the Association between NQO1 Pro187Ser Polymorphism and Colorectal Cancer in Asians. Tumor Biology, 35, 2111-2116. http://dx.doi.org/10.1007/s13277-013-0740-0

[27] Zhang, H., Wen, X. and Lu, X. (2013) Association between NAD(P)H:Quinone Oxidoreductase 1 rs1800566 Polymorphism and Risk of Bladder Cancer. Tumor Biology, 34, 3377-3381. http://dx.doi.org/10.1007/s13277-012-0633-7

[28] Lajin, B. and Alachkar, A. (2013) The NQO1 Polymorphism C609T (Pro187Ser) and Cancer Susceptibility: A Comprehensive Meta-Analysis. British Journal of Cancer, 109, 1325-1337. http://dx.doi.org/10.1038/bjc.2013.357

[29] Thakkinstian, A., McElduff, P., D’Este, C., Duffy, D. and Attia, J. (2005) A Method for Meta-Analysis of Molecular Association Studies. Statistics in Medicine, 24, 1291-1306. http://dx.doi.org/10.1002/sim.2010

[30] Eickelmann, P., Schulz, W.A., Rohde, D., Schmitz-Dräger, B. and Sies, H. (1994) Loss of Heterozygosity at the $\mathrm{NAD}(\mathrm{P}) \mathrm{H}$ :Quinone Oxidoreductase Locus Associated with Increased Resistance against Mitomycin C in a Human Bladder Carcinoma Cell Line. Biological Chemistry Hoppe-Seyler, 375, 439-445. http://dx.doi.org/10.1515/bchm3.1994.375.7.439

[31] Siegel, D., Anwar, A., Winski, S.L., Kepa, J.K., Zolman, K.L. and Ross, D. (2001) Rapid Polyubiquitination and Proteasomal Degradation of a Mutant Form of NAD(P)H:Quinone Oxidoreductase 1. Molecular Pharmacology, 59, $263-$ 268.

[32] Siegel, D., McGuinness, S.M., Winski, S.L. and Ross, D. (1999) Genotype-Phenotype Relationships in Studies of a Polymorphism in NAD(P)H:Quinone Oxidoreductase 1. Pharmacogenetics, 9, 113-121. http://dx.doi.org/10.1097/00008571-199902000-00015

[33] Misra, V., Grondin, A., Klamut, H.J. and Rauth, A.M. (2000) Assessment of the Relationship between Genotypic Status of a DT-Diaphorase Point Mutation and Enzymatic Activity. British Journal of Cancer, 83, 998-1002. http://dx.doi.org/10.1054/bjoc.2000.1359

[34] Hajos, A.K. and Winston, G.W. (1991) Purified NAD(P)H-Quinone Oxidoreductase Enhances the Mutagenicity of Dinitropyrenes in Vitro. Journal of Biochemical Toxicology, 6, 277-282. http://dx.doi.org/10.1002/jbt.2570060407 